http://jmscr.igmpublication.org/home/

ISSN (e)-2347-176x ISSN (p) 2455-0450

crossref DOI: https://dx.doi.org/10.18535/jmscr/v8i5.57

Journal Of Medical Science And Clinical Research

\title{
Prospective Study of Laparoscopy in Patients with Chronic Abdominal Pain
}

\author{
Authors \\ Amarjeet E Tandur*, Aftab S Shaikh, Shalmali Dharmadhikari, Ajay H Bhandarwar, \\ Ameya Tibude, Shekhar Jadhav, Sagar Chavan \\ Department of General Surgery, Grant Government Medical College \& Sir JJ group of Hospitals, Byculla \\ Mumbai-400008, India \\ *Corresponding Author \\ Amarjeet E Tandur
}

\begin{abstract}
Background: The intention of this prospective study is to highlight the utility of laparoscopy in patients vexed with chronic abdominal pain as it aides in diagnosis followed by therapeutic intervention in the same sitting.

Material and Methods: A prospective study was performed of 100 patients who underwent laparoscopy for chronic abdominal pain (more than or equal to 6 weeks), with average age of presentation being 34.6 years. Standard laparoscopic procedure was followed.

Results: A diagnosis could be clinched in $91 \%$ of the patients, with laparoscopic adhesiolysis (30\%) being the commonest procedure. The average duration of procedure was 62.15 minutes and average duration of stay was 4.2 days. Therapeutic efficacy of $80 \%$ was attained.

Conclusion: Laparoscopy-a minimally invasive, safe and effective modality has showed its utility in cases of chronic abdominal pain where conventional investigation methods have failed us. This invaluable tool has a high diagnostic accuracy and therapeutic efficacy. It allows us to come to a diagnosis with the added advantage of allowing a therapeutic intervention in the same sitting in most cases, thus avoiding further hospitalisation/exploration of the abdomen.

Keywords: Laparoscopy, chronic abdominal pain, diagnosis and intervention.
\end{abstract}

\section{Introduction}

Chronic abdominal pain can be a diagnostic challenge. Patients with chronic abdominal pain are amongst the most difficult to manage. Potentially it can be unrewarding for both the patient and the treating physician as these patients undergo a myriad of tests without identifying the etiology of pain. Surgical consultation often occurs late after other modalities have failed to provide resolution of their symptomatology. ${ }^{1}$

The introduction of laparoscopic surgery and recent advances in laparoscopy have been increasingly recognized as a procedure that offers more information at visual assessment of intraabdominal condition for diagnosis and prompt intervention. Laparoscopy has a significant diagnostic and therapeutic role in patients with trauma, abdominal cancers, acute and chronic abdominal pain. In case of diagnostic uncertainty, laparoscopy may help to avoid unnecessary laparotomy, provide accurate diagnosis and helps to plan surgical treatment. ${ }^{2}$

Laparoscopy is the only method of visualizing the pathologic anatomy of abdominal cavity in 
clinical practice 7 sometimes even radiological investigations fail to identify them. Laparoscopy allows surgeons to see and treat many abdominal changes that could not be diagnosed otherwise. Hence diagnostic laparoscopy should be considered for patients suffering from acute and chronic abdominal pain, as it is minimally invasive, safe, efficacious and effective diagnostic modality and can be performed rapidly, safely with minimal sequel. ${ }^{3}$

\section{Material and Methods}

A prospective study was conducted on patients with chronic pain in abdomen with failed conservative managements panning from the period of July 2015-October 2019 at our tertiary care centre. A sample size of 100 patients between the age group of 12-60 years was selected with the average age of presentation between 34.60 years. Youngest patient was 16 years old and oldest 57 years old. $52 \%$ of the study population was female. Abdominal pain was considered to be chronic if the duration was more than or equal to 6 weeks. In all patients selected for the study, the chronic pain was of unclear aetiology, despite physical, laboratory, and radiographic evaluation.

\section{Inclusion Criteria}

1. All cases of pain in abdomen with duration more than or equal to 6 weeks.

2. Age group between 12 to 60 years of age.

3. Irrespective of sex

4. Irrespective of previous abdominal surgery.

5. USG (abdomen pelvis) suggestive of no significant abnormality.

\section{Exclusion Criteria}

1. Age below 12 years and above 60 years.

2. Pregnant women.

3. Patient not consenting for procedure.

4. Trauma patients and patients with acute abdominal pain.

\section{Study Design}

-Prospective Study Of minimum 100 patients selected as per the above inclusion criteria.

-Thorough history was taken regarding the following: Location, intensity, character, duration of pain, aggravating and relieving factors.

-Detailed clinical examination of all patients was carried out

-Each case was thoroughly investigated:

- All relevant blood investigations

- Urine analysis and culture

- Additional laboratory investigations were chosen on the basis of history and physical examination

-Written informed consent was obtained from patients. The personal details of patients included in the study will not be revealed.

-All patients underwent X-ray abdomen, Chest XRay PA

-Pre-operative pulmonary function test was done as when required.

-Pre-operative, intra-operative \& post- operative period was monitored including post-operative analgesia requirement \& pain assessment by visual analogue score.

-Post-operative follow up at 6 and 12 months included symptomatology, clinical examination of the patient, $X$ ray abdomen and ultrasound (abdomen pelvis) if required.

\section{Operative Technique}

After induction of general anaesthesia, patient was be placed either flat or in a modified lithotomy position. Patient is catheterized, which avoids bladder injury. Nasogastric intubation is done if stomach is distended. In patients with previous history of surgery pneumoperitoneum is established by Verees needle at palmers point. Virgin abdomens were accessed through open umbilical Hasson's technique. General inspection of entire abdomen is carried out starting from supracolic compartment examining stomach, liver, spleen in reverse Trendelenburg position. Infracolic compartment examined in Trendelenburg position looking for pathologies in 
small bowel, colon, pelvic organs tilting table sideways as required for particular organ. Additional ports are placed as needed.

\section{Evaluation of Outcome}

Positive outcome-if patient comes with less or no pain during follow up at 6 and 12 months.

Negative outcome-if patient complaints of persistent or worsening pain during follow up at 6 and 12 months.

\section{Results}

Table 1: Location of Pain Over Abdomen

\begin{tabular}{|l|c|}
\hline LOCATION OF PAIN & PERCENTAGE (\%) \\
\hline Diffuse,All over abdomen & 58 \\
\hline Lower abdominal and periumbilical & 24 \\
\hline Right lower & 10 \\
\hline Central & 5 \\
\hline Right lumbar & 1 \\
\hline Epigastric & 1 \\
\hline Left iliac fossa & 1 \\
\hline
\end{tabular}

Table 2: Operative history

\begin{tabular}{|l|c|}
\hline History of operation & Number of cases \\
\hline Present & 19 \\
\hline Absent & 81 \\
\hline Total & 100 \\
\hline
\end{tabular}

Table 2 shows in our study 19 patients had previous history of abdominal operation. 4 patients - history of tubal ligation, 4 patients history of LSCS, 4patients - open appendicectomy, 3 patients - ventral hernia repair, 2 patients- history exploration of abdomen and 2 patient - abdominal hysterectomy.

The diagnosis at laparoscopy has been summarised in table 3 .

Table 3: Diagnosis at laparoscopy

\begin{tabular}{|l|c|}
\hline DIAGNOSIS & NUMBER OF CASES (n) \\
\hline Adhesions & 30 \\
\hline Abdominal tuberculosis & 21 \\
\hline Chronic appendicitis & 16 \\
\hline Mesenteric Lymphadenopathy & 9 \\
\hline Endometriosis & 8 \\
\hline Ovarian cyst & 3 \\
\hline Intessusception & 2 \\
\hline Meckel's diverticulum & 2 \\
\hline Normal Study & 9 \\
\hline TOTAL & 100 \\
\hline
\end{tabular}

$91 \%$ of the patients were found to have an abnormality on laparoscopic examination. Majority of the patients were found to have adhesions, followed closely by abdominal tuberculosis and chronic appendicitis. A small number of patients were encountered to have mesenteric lymphadenopathy, endometriosis, ovarian cyst, intussusception and Meckel's diverticulum. Out of 100 patients who underwent laparoscopy, only 9 patients had normal study.

Table 4: Procedures Performed

\begin{tabular}{|l|c|}
\hline PROCEDURES & NUMBER OF CASES \\
\hline Laparoscopic adhesiolysis & 30 \\
\hline Laparoscopic appendectomy & 16 \\
\hline Laparoscopic lymph node biopsy & 14 \\
\hline Laparoscopic peritoneal biopsy & 11 \\
\hline Laparoscopic omental biopsy & 5 \\
\hline Laparoscopic biopsy of pelvic lesions & 5 \\
\hline Laparoscopic electrocoagulation & 3 \\
\hline Laparoscopic aspiration of ovarian cyst & 2 \\
\hline Laparoscopic ovarian cystectomy & 1 \\
\hline Meckel's diverticulectomy & 1 \\
\hline $\begin{array}{l}\text { Laparoscopic reduction } \\
\text { intussusception }\end{array}$ & 1 \\
\hline Resection and anastomosis & 2 \\
\hline Normal study & 9 \\
\hline
\end{tabular}

The commonest finding i.e. adhesions were found in 30 cases (out of which 6 females and 7 males had undergone surgery previously). In these patients, appendix was essentially normal and hence only adhesiolysis was done. Pelvic adhesions, anterior abdominal wall adhesions were the common findings and all cases were managed laparoscopically using harmonic scalpel, cold scissors and monopolar cautery.

The 21 cases of abdominal tuberculosis were managed by laparoscopic peritoneal, lymph node and omental biopsy based on laparoscopic findings of tubercles on peritoneum, multiple mesenteric lymph nodes, omental caking, cocoon abdomen, plastered abdomen whose biopsy\& GeneXpert MTB/RIF report came as tuberculosis. These patients were started on anti Kochs treatment.

16 patients found to have thickened appendix underwent laparoscopic appendectomy. Histopathological examination confirmed the diagnosis as chronic appendicitis. 


\section{JMSCR Vol||08||Issue||05||Page 305-311||May}

9 patients had non-specific mesenteric lymphadenitis confirmed on histopathology examination after biopsy.

8 patients had features suggestive of Endometriosis.3 underwent electrocoagulative ablation, rest were biopsied and started on hormonal therapy after confirmation on histopathological examination.

Of the 3 cases found to have an ovarian cyst, 2 cases underwent ovarian cyst aspiration and 1 patient underwent ovarian cystectomy whose histopathology turned out to be a mucinous ovarian cyst.

2 patients had Meckel's Diverticulum on bowel walk. One had Diverticulitis mimicking as appendicitis and had to undergo laparoscopic resection and anastomosis, one underwent diverticulectomy.

Intussusception was found in 2 patients. One had ileocaecal intussusception and underwent right hemicolectomy and other had ileo-ileal intussusception, only reduction was done. This patient was later subjected to contrast CT of abdomen which showed multiple polyps in ileum and jejunum.

Hence Diagnostic Accuracy was 91\%. Only 9 patients had normal findings on laparoscopy.

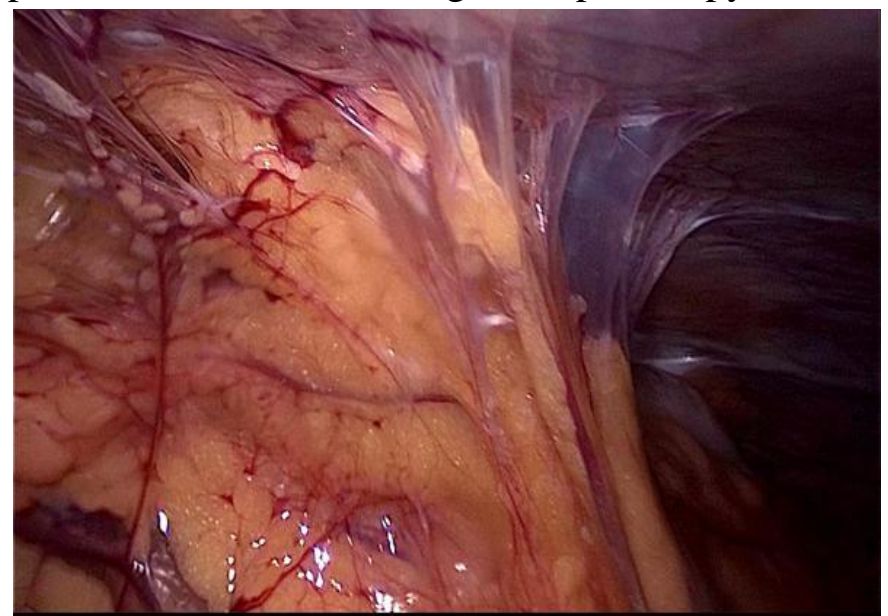

Figure 1: Adhesions to anterior abdominal wall

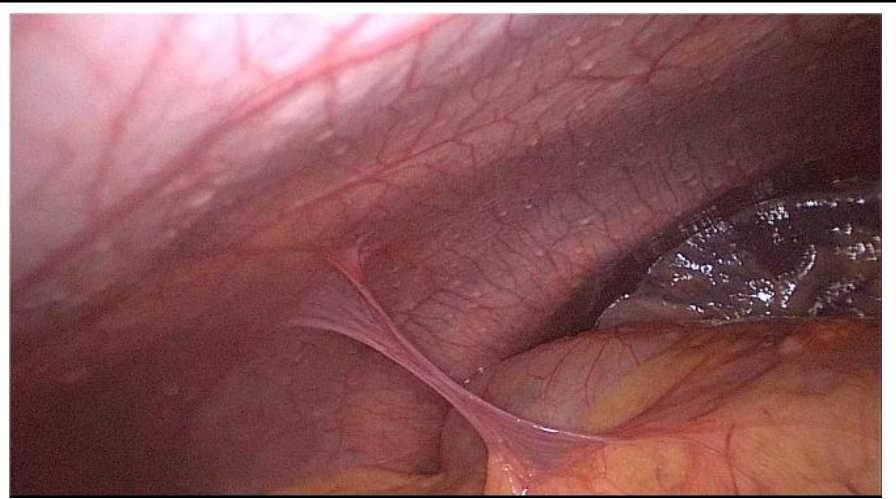

Figure 2: Adhesions and tubercles in abdominal Koch's

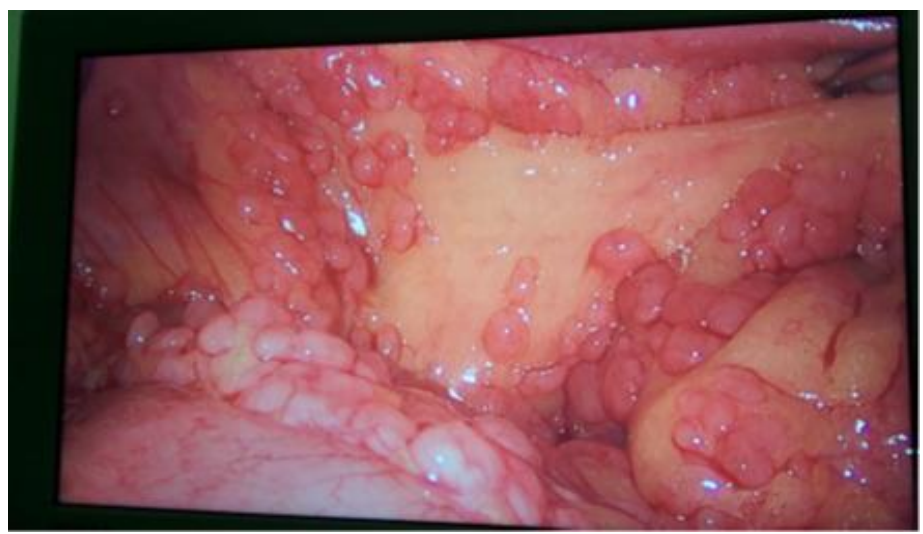

Figure 3: Tubercles on mesentery

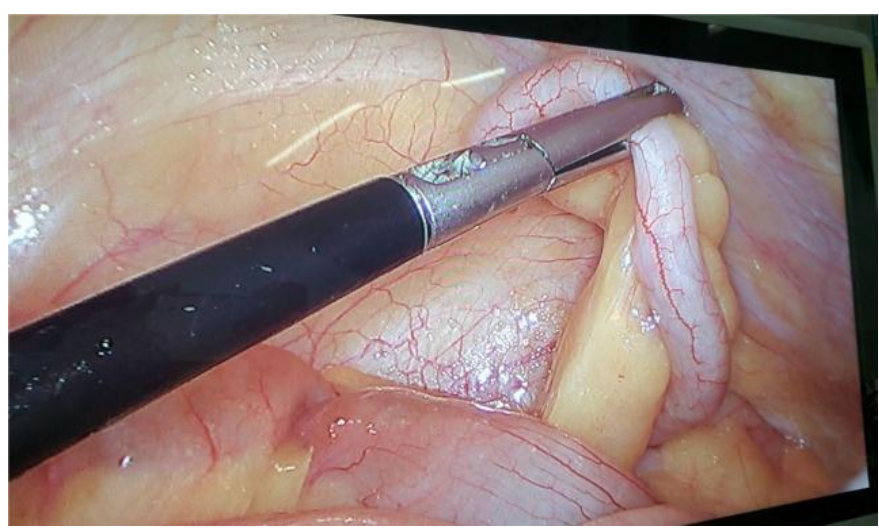

Figure 4: Chronic inflamed appendix

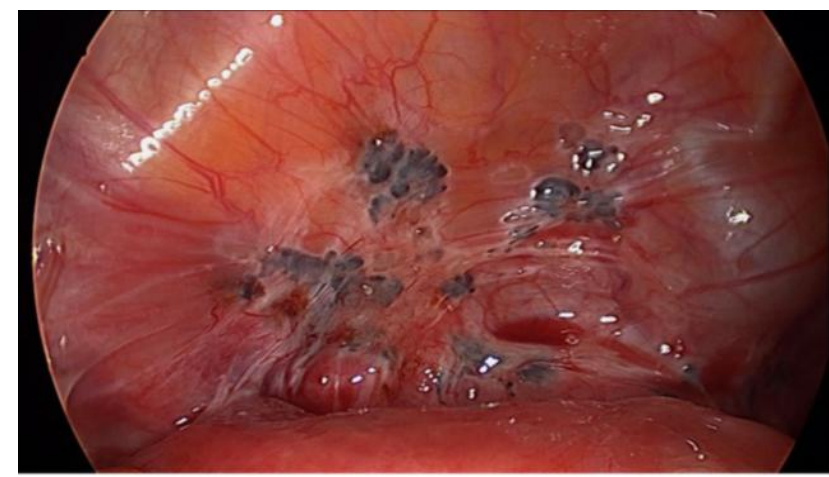

Figure 5: Endometrial lesion on pelvic wall 


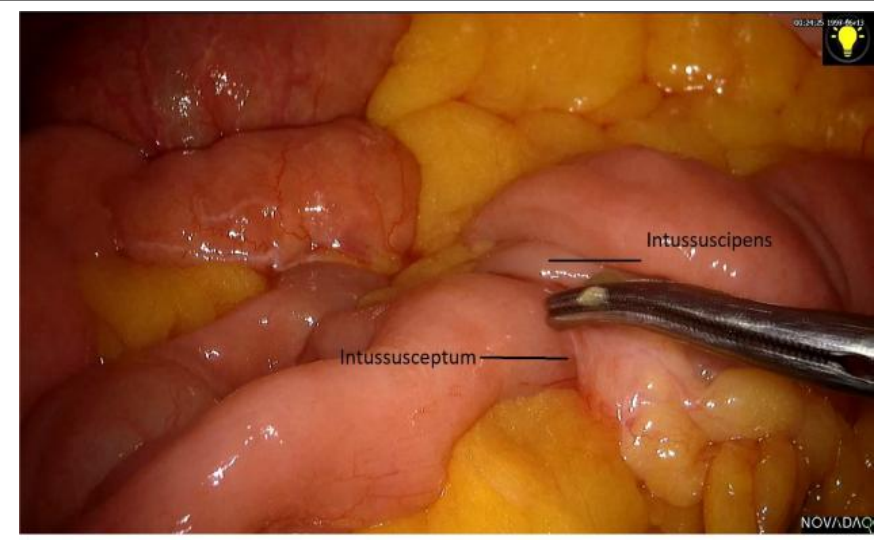

Figure 6: Ileo caecal intussusception

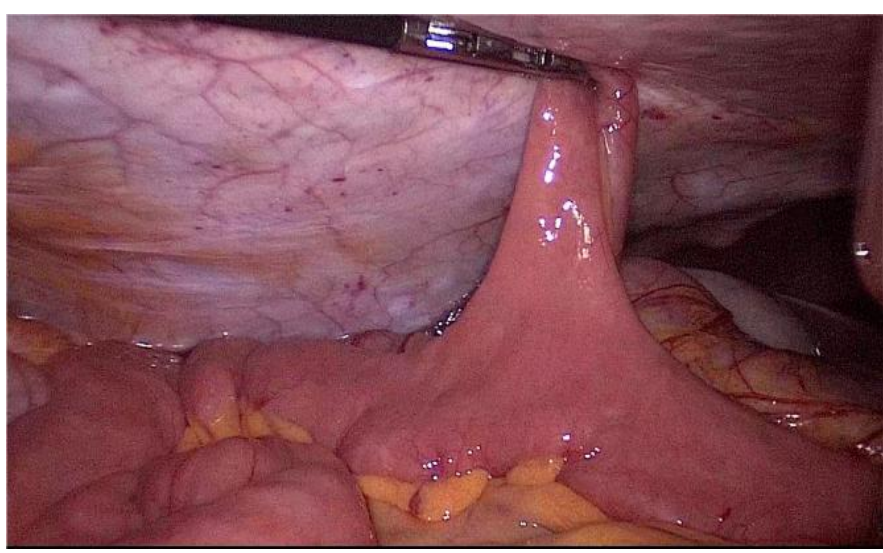

Figure 7 Meckel's diverticulum

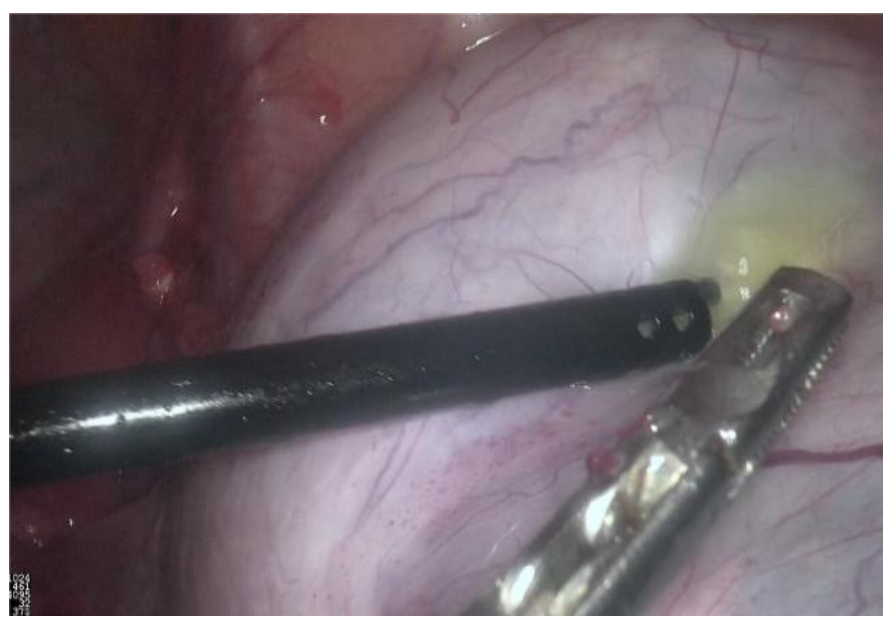

Figure 8 Ovarian cyst aspiration

Complications-In most of our cases there was no post-operative complications except in ten patients who developed surgical site infection which was managed conservatively by appropriate antibiotic cover and alternate day wound dressing, (ClavienDindo Grade 2). No port site hernias or visceral injuries were encountered. No mortality was encountered in our study group.
Duration of hospital stay: Post-operative hospital stay ranged from 2 to 10 days with a mean duration of stay of 4.2 days.

Duration of procedure: The average length of the operative time was 62.15 minutes. All procedures were done laparoscopically.

Follow up: During the follow up period, all patients were re-evaluated for pain.

The patients were reviewed at 6months and 12 months post operatively. Subjective assessment of pain was done during the follow up and positive outcome (less pain or disappearance of pain i.e.80\%) was noted and negative outcome (persistence of pain or worsening pain i.e. 20\%) was also noted.

Hence on follow up 80 patients had pain relief achieving a Therapeutic Efficacy of $80 \%$.The following tables compare the pre-operative and post-operative Visual Analog Scale (VAS) scores on follow up at 6 and 12 months.

Table 5: Pre-operative Visual analogue scores

\begin{tabular}{|c|c|}
\hline Percentage of patients (\%) & Pre-operative VAS score \\
\hline 92 & $4-5$ (moderate pain) \\
\hline 6 & $6-7$ (severe pain) \\
\hline 2 & $1-3$ (mild pain) \\
\hline
\end{tabular}

Table 6: Post-operative visual analogue score

\begin{tabular}{|c|c|c|}
\hline $\begin{array}{c}\text { Percentage of } \\
\text { patients } \\
(\%)\end{array}$ & $\begin{array}{c}\text { Post-operative VAS } \\
\text { score at 6months }\end{array}$ & $\begin{array}{c}\text { Post operative } \\
\text { VAS score at } 12 \\
\text { months }\end{array}$ \\
\hline 74 & $1-3$ (mild pain) & 0 (no pain) \\
\hline 6 & $4-5$ (moderate pain) & 0 (no pain) \\
\hline 18 & $4-5$ (moderate pain) & $\begin{array}{c}4-5 \text { (moderate } \\
\text { pain) }\end{array}$ \\
\hline 2 & $1-3$ (mild pain) & $1-3$ (mild pain) \\
\hline
\end{tabular}

\section{Discussion}

Diagnostic laparoscopy makes it possible for the surgeon to directly visualize the contents of the abdominal cavity better than any other investigative modality. The study confirmed that in this difficult patient group, laparoscopy could safely identify abnormal findings and can improve the outcome in a majority of the cases. In this study 100 patients were considered who were admitted in the surgical wards in a Tertiary Care Centre, between July 2015 to October 2019 .In our study 91 patients had pathological findings 
identified at the time of laparoscopy. The results of our study compare favourably with similar studies done previously as illustrated below.

Effectiveness of appendicectomy in alleviating pain in patients with chronic abdominal pain

Table 7: Pain relief post appendicectomy

\begin{tabular}{|c|c|}
\hline STUDY & SUCCESS RATE \\
\hline${\text { Fayez et } \mathrm{al}^{4}}^{4}$ & $95 \%$ \\
\hline${\text { Raymond et } \mathrm{al}^{5}}$ & $74 \%$ \\
\hline Present study & $96 \%$ \\
\hline
\end{tabular}

Thus, this proves that appendectomy done for patients with chronic right lower abdominal pain with inconclusive diagnosis, does in fact cause resolution of pain, further highlighting the need to include investigation of appendix in the work up of chronic abdominal pain, when no other diagnosis is readily apparent.

Adhesions being the commonest cause is in tandem with various studies as follows-

Table 8: Percentage of patients with adhesions

\begin{tabular}{|l|c|}
\hline STUDY & $\begin{array}{r}\text { PERCENTAGE OF PATIENTS } \\
\text { WITH ADHESION }\end{array}$ \\
\hline Lavonius $\mathrm{M} \mathrm{et} \mathrm{al}^{6}$ & 63 \\
\hline Klingensmith et al $^{7}$ & 56 \\
\hline Raymond P et al $^{5}$ & 55 \\
\hline Onders RP et al & \\
\hline $\begin{array}{l}\text { Kinnaresh Ashwin } \\
\text { Kumar Baria }\end{array}$ & 55 \\
\hline Present study & 14 \\
\hline
\end{tabular}

The therapeutic efficacy of laparoscopic adhesiolysis in our study $(77.77 \%)$ is comparable to the likes of Dunker $S$ et al ${ }^{10}$ (positive outcome in more than $50 \%$ cases) and Vafa Shayani et al ${ }^{11}(77.8 \%$ cure rate).

Diagnostic accuracy and therapeutic efficacy can be demonstrated by the tables $9 \& 10$

Table 9: Diagnostic Accuracy

\begin{tabular}{|l|c|c|}
\hline STUDY & $\begin{array}{c}\text { NO OF } \\
\text { PATIENTS }\end{array}$ & $\begin{array}{c}\text { DIAGNOSTIC } \\
\text { ACCURACY }\end{array}$ \\
\hline Raymond P et al $^{5}$ & 70 & $85.7 \%$ \\
\hline Karl Miller et al $^{12}$ & 59 & $89.8 \%$ \\
\hline Klingensmith et al $^{7}$ & 34 & $65 \%$ \\
\hline Schrenk P et al & 92 & $87 \%$ \\
\hline $\begin{array}{l}\text { Kinnaresh Ashwin } \\
\text { Kumar Baria }\end{array}$ & 50 & $90 \%$ \\
\hline Andreollo et al $^{14}$ & 168 & $86.3 \%$ \\
\hline Salky BA et al & & $76 \%$ \\
\hline Kumar R et al & 265 & $94 \%$ \\
\hline $\begin{array}{l}\text { Gouda M EI Labban } \\
\text { and Emad N }\end{array}$ & 150 & $83.3 \%$ \\
\hline Present study & 30 & $91 \%$ \\
\hline
\end{tabular}

Table 10: Therapeutic Efficacy

\begin{tabular}{|l|c|c|}
\hline STUDY & $\begin{array}{c}\text { NO OF } \\
\text { PATIENTS }\end{array}$ & $\begin{array}{c}\text { THERAPEUTIC } \\
\text { EFFICACY (\%) }\end{array}$ \\
\hline Klingensmith et al $^{7}$ & 34 & 73 \\
\hline Vafa Shayani et al $^{11}$ & 18 & 77.8 \\
\hline Miller K et al $^{12}$ & 59 & 89.3 \\
\hline $\begin{array}{l}\text { Kinnaresh Ashwin } \\
\text { Kumar Baria }\end{array}$ & 50 & 94 \\
\hline Chao K et al $^{18}$ & 41 & 78 \\
\hline Onders RP et al $^{8}$ & 70 & 70 \\
\hline Paajanen et al & & $>70$ \\
\hline Present study & 35 & 80 \\
\hline
\end{tabular}

Thus, our study is congruent with recent literature in terms of diagnostic \& therapeutic effiacacy. Hence diagnostic laparoscopy is a tool to manage difficult chronic pain abdominal conditions \& further determine the course of patient in hospitals

\section{Conclusion}

Laparoscopy has an effective diagnostic accuracy and therapeutic efficacy in the management of patients who present to us with chronic abdominal pain, especially in whom conventional methods of investigations have failed to elicit a cause for the pain and in whom conservative management with antibiotics, proton pump inhibitors and antispasmodics/analgesics failed to relive the symptoms.

Diagnostic laparoscopy has a high diagnostic and therapeutic efficacy. Ability to pinpoint a cause for the abdominal pain or exclude a more major cause for pain not only avoids further investigations but also plays a significant role in alleviating the fears in the minds of the patients. Not only does laparoscopy point to a diagnosis, it has the added advantage that therapeutic intervention can be done at the same sitting in most cases thus avoiding another hospitalization or another exploration of the abdomen.

Laparoscopy prevents unnecessary laparotomy in a significant number of cases.

Diagnostic laparoscopy has a definitive role in the management of patients with chronic pain abdomen and should be an important investigative tool in the armamentarium of all practicing surgeons. 


\section{References}

1. Ferrell BR. The impact of pain on quality of life: A decade of research. Nurs Clin North Am.1995;30:609-24.

2. C. Palanivelu, Art of laparoscopic surgery, Textbook and atlas, Chapter 12-Diagnostic laparoscopy- Indication, tuberculosis and adhesiolysis, Jaypeepublishers,2005, 1st edition, vol 1,p.152-177.

3. Tehemton E Udwadia, Laparoscopic surgeries in developing countries, Jaypee brothers,1997,1st edition,p.200-237.

4. Fayez J.A., Toy NJ and Flanagan TM : The appendix as the cause of chronic lower abdominal Pain: Am.J. obstet Gynecol: 1995;172:122-3.

5. Raymond P, Onders MD, Elizabeth A, Mittendorf MD: Utility of laparoscopy inchronic abdominal Pain. Surg : 2003; 134(4): 549-54.

6. Lavonius $\mathrm{M}$, et al: Laparoscopy for chronic abdominal Pain. Surg Laparosc \& endosc: 1999; 9: 42-4.

7. Klingensmith ME, soybel DI, Brooks DC: Laparoscopy for chronic abdominal Pain Surg Endosc: 1996; 10(11): 1085-7.

8. Raymond P, Onders MD, Elizabeth A, Mittendorf MD :Utility of laparoscopy inchronic abdominal Pain. Surg : 2003; 134(4): 549-54.

9. Kinnaresh ashwin kumar baria role of laparoscopy in diagnosis and management of chronic Abdominal pain indian j.sci.res. 4(1) : 65-68, 2013

10. Dunker MS ,Bemelman WA, Vijn A, et al: Long-term outcomes and quality of life after laparoscopic adhesiolysis for chronic abdominal pain. J Am Assoc Gynecol Laparosc 2004; 11:36-41.

11. Vafa Shayani, Claudine Siegert, and Philip Favia. The Role of Laparoscopic Adhesiolysis in the Treatment of Patients with Chronic Abdominal Pain or Recurrent Bowel Obstruction, JSLS; 2002: Apr-Jun; 6(2): 111-114.
12. Karl Miller MD, Edith Mayer MD, Erich Moritz HD: The role of laparoscopy inchronic \& recurrent abdominal Pain. Am J. Surg: 1996:172; 353-7.

13. Schrenk P, Woisetschläger R, Wayand WU, Rieger R, Sulzbacher H.Diagnostic laparoscopy: a survey of 92 patients. Am J Surg. 1994Oct;168(4):348-51.

14. Andreollo NA, Coelho Neto Jde S, Lopes LR, Brandalise NA, Leonardi LS.Laparoscopy in the diagnosis of intraabdominal diseases. Analysis of 168cases. Rev Assoc Med Bras. 1999 JanMar;45(1):34-8.

15. Salky BA, Edye MB: The role of laparoscopy in the diagnosis and treatment of abdominal Pain syndromes; Surg Endosc: 1998; 12(7):911-4.

16. Kumar R, Saxena N, Chaudhary P, Ahirwar N, Gautam S, Munjewar C, et al.Role of diagnostic laparoscopy in patients with non-specific abdominal pain andits correlation with clinical and radiographic findings. Hell J Surg [Internet]. 2016

17. Gouda M El-labban and Emad N Hokkam, The efficacy of laparoscopy in thediagnosis and management of chronic abdominal pain. J minim Access Surg2010 Oct - Dec; 6 (4): 95-99.

18. Chao K, Farrell S, Kerdemelidis P, Tulloh B. Diagnostic laparoscopy for chronicright iliac fossa pain: a pilot study. Aust N Z J Surg. 1997 Nov;67(11):789-91

19. Paajanen, Hannu, Julkunen, Kristiina, Waris, Heidi. Laparoscopy in Chronic Abdominal Pain: A Prospective Nonrandomized Long-term Follow-up Study, Journal of Clinical Gastroenterology. Feb 2005;39(2), p. 11014. 